06

\title{
Роль добавок графена в стойкости оксида алюминия хрупкому разрушению при импульсных электрофизических воздействиях
}

\author{
(C) А.В. Кузнецов, ${ }^{1}$ В.А. Морозов, ${ }^{2}$ Г.Г. Савенков, ${ }^{1,3,4}$ В.В. Столяров ${ }^{5}$ \\ ${ }^{1}$ Машиностроительный завод „Армали“, \\ 198097 Санкт-Петербург, Россия \\ ${ }^{2}$ Санкт-Петербургский государственный университет, \\ 199034 Санкт-Петербург, Россия \\ ${ }^{3}$ Санкт-Петербургский государственный технологический институт (технический университет), \\ 190013 Санкт-Петербург, Россия \\ ${ }^{4}$ Физико-технический институт им. А.Ф. Иоффре РАН, \\ 194021 Санкт-Петербург, Россия \\ ${ }^{5}$ Институт машиноведения им. А.А. Благонравова РАН, \\ 101000 Москва, Россия \\ e-mail: sav-georgij@yandex.ru
}

Поступило в Редакцию 15 июля 2020 г.

В окончательной редакции 5 октября 2020 г.

Принято к публикации 7 октября 2020 г.

\begin{abstract}
Приведены результаты исследования динамической прочности нанокерамики $\mathrm{Al}_{2} \mathrm{O}_{3}$ с различным содержанием пятислойного графена под действием сильноточного электронного пучка наносекундной длительности и высоковольтного электрического разряда также наносекундной длительности. Было установлено, что при импульсной нагрузке увеличение в композите содержания графена приводит к охрупчиванию нанокомпозита.
\end{abstract}

Ключевые слова: металлокерамический композит, графен, сильноточный электронный пучок, высоковольтный разряд.

DOI: $10.21883 /$ JTF.2021.03.50527.247-20

\section{Введение}

В последнее десятилетие в области фундаментальноприкладной науки и в промышленности увеличивается интерес к металлокерамическим композитам на основе оксида алюминия [1-3]. Потребность в порошке оксида алюминия для изготовления композитов на его основе, согласно [4], должна была достигнуть в 2020 г. порядка 850 млн. долларов. Композиты на основе оксида алюминия обладают высокой прочностью, но соответственно проявляют и высокую хрупкость по сравнению с металлическими материалами. Вероятным решением данной проблемы является использование углеродных наночастиц разного типа, включая графен [5]. Композиты с графеном обладают рядом уникальных электрофизических, механических, тепловых свойств [6-10]. Особый интерес представляет композит на основе нанопорошка корунда и малых добавок многослойного графена, полученный методом искрового плазменного спекания (spark plasma sintering (SPS)) [9].

Метод SPS позволяет получать керамический композит с плотностью, близкой к теоретическому значению, и размером зерен, близким к размеру частиц исходного порошка. В то же время предполагается, что, добавляя чешуйки графена, которые могут расположиться на границах зерен керамической матрицы, можно вызвать значительное уменьшение хрупкости композита $\mathrm{Al}_{2} \mathrm{O}_{3}$ вследствие повышения адгезивных свойств субмикрон- ных элементов [9]. Некоторые работы подтверждают это в испытаниях на изгиб при статическом сжатии [10].

Одним из сравнительно новых видов применения композитов на основе оксида алюминия является их использование в изделиях динамической защиты, например, в бронежилетах [11,12]. Однако сведения о прочностных свойствах таких композиций в экстремальных условиях нагружения в микро- и наносекундной областях практически отсутствуют. В этой связи хорошим методом изучения динамических характеристик композитов на основе оксида алюминия являются импульсные электрофизические воздействия, которые позволяют применять образцы малого размера, что является неоспоримым преимуществом перед другими динамическими методами.

Целью настоящей работы является исследование сравнительной прочности и характера разрушения нанокомпозита $\mathrm{Al}_{2} \mathrm{O}_{3}$ /graphene при увеличении содержания графена в условиях импульсных электрофизических воздействий: сильноточного электронного пучка и высоковольтного электрического разряда.

\section{1. Материал и экспериментальные методики}

Импульсные электрофизические воздействия осуществлялись при помощи сильноточного электронного пучка (СЭП) наносекундной длительности и высоко- 
Микротвердость и прочность на изгиб чистой и композиционной керамики $\mathrm{Al}_{2} \mathrm{O}_{3}$

\begin{tabular}{l|c|c|c}
\hline Дисперсность порошка $\mathrm{Al}_{2} \mathrm{O}_{3}$ & Массовая доля графена, \% & Микротвердость, $\mathrm{GPa}$ & Прочность на изгиб, МРа \\
\hline Поликристаллический, $1-2 \mu \mathrm{m}$ & 0 & $15.5[13]$ & $550[13]$ \\
Субмикрокронный, $150 \mathrm{~nm}$ & 0 & $22.1[14]$ & $200[14]$ \\
Нанокристаллический, $45 \mathrm{~nm}$ & 2 & $27.4[14]$ & $260[14]$
\end{tabular}

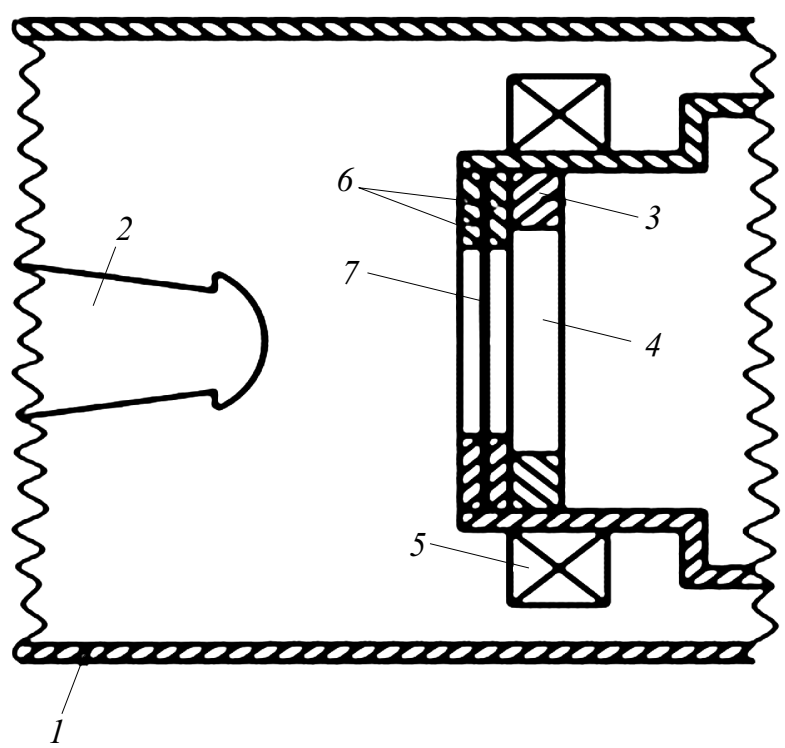

Pис. 1. Схема нагружения образцов: 1 - вакуумная камера, 2 - катод, 3 - стальное кольцо, 4 - образец, 5 пояс Роговского (измеритель тока электронного пучка), 6 прижимные кольца, 7 - титановая или алюминиевая фольга.

вольтного разряда электрического тока на образцы оксида алюминия с добавками графена, которые представляли собой диски диаметром $15 \mathrm{~mm}$ и толщиной $\sim 2.5 \mathrm{~mm}$. Массовая доля графена в образцах составляла от 0.5 до $2 \%$.

В таблице представлены данные из литературных источников по микротвердости и прочности на изгиб композитной керамики Видно, что микротвердость алюминиевой керамики значительно возрастает с использованием нанопорошка $\mathrm{Al}_{2} \mathrm{O}_{3}$ и введением графена. Однако увеличение микротвердости в алюминиевой керамике приводит к снижению вязкости разрушения [11] и с точки зрения динамических защитных свойств это является не очень хорошим признаком.

Что касается прочности на изгиб, то она резко уменьшается при переходе от порошка большого размера к порошку наноразмера. Однако, как видно из таблицы, введение графена до $2 \%$ может частично компенсировать снижение прочности на изгиб.

В качестве источника возбуждения СЭП использовался импульсный сильноточный ускоритель электронов (генератор коротких высоковольтных импульсов) ГКВИ-300 со средней энергией электронов в спектре $100-300 \mathrm{keV}$ и длительностью импульса напряжения на полувысоте $\sim 30-300 \mathrm{~ns}$ с амплитудой тока $I \approx 2 \mathrm{kA}$ и энергией $E \approx 60 \mathrm{~J}$. Схема эксперимента приведена на рис. 1.

Диаметр пучка электронов - $10 \mathrm{~mm}$. Образец 4 в форме диска находился в стальном кольце 3 с внешним диаметром $32.5 \mathrm{~mm}$ и внутренним диаметром $\sim 15 \mathrm{~mm}$ высотой $\sim 2.5 \mathrm{~mm}$. Воздействие электрического пучка, генерировавшегося с катода 2, на образец осушествлялось в вакуумной камере 1 при давлении остаточных газов $\sim 10^{-2} \mathrm{~Pa}$ и температуре помещения $20^{\circ} \mathrm{C}$. Образец устанавливался в стальное кольцо перпендикулярно летящему пучку электронов. Поскольку в работе применялся в качестве источника электронов катод, работающий в режиме взрывной эмиссии, то, как было сказано выше, кроме электронного пучка существенный вклад в нагружение и нагрев образца может вносить катодный факел (металлическая плазма), возникающий при генерации пучка $[15,16]$. Поэтому все эксперименты проводились с отсечкой катодного факела [10] путем установки на кольцо 3 титановой фольги толщиной $50 \mu \mathrm{m}$ или алюминиевой фольги толщиной $20 \mu \mathrm{m}$, что в целом приводило к уменьшению энергетических параметров пучка в два-три раза (титановая фольга) и на $20 \%$ для алюминиевой фольги [17].

Потенциально возможными действующими факторами импульсного электронного пучка на образец являются: тепловое воздействие, механическое и ударноволновое [18]. Из этих трех факторов наибольший вклад в разрушение образца, как показывают оценочные расчеты, вносит ударно-волновое воздействие [18]. Амплитуду давления pm, создаваемого ударной волной, возникающей при действии на образец электронного пучка, можно оценить по зависимости

$$
p_{m}=\frac{\gamma \Delta E}{V},
$$

где $\gamma$ - коэффициент Грюнайзена, $\Delta E-$ поглощенная образцом энергия пучка, $V_{s}$ - объем образца. Коэффициент Грюнайзена определим по приближенной зависимости $[19,20]$ :

$$
\gamma=\frac{3}{2}\left(\frac{1+v}{2-3 v}\right),
$$

где $v$ - коэффициент Пуассона. Коэффициент Пуассона для оксида алюминия $v=0.23$ [21], тогда в соответствии c $(2), \gamma \approx 1.41$. Используя данные для параметров пучка, приведенные в [18] (они практически совпадают с параметрами пучка в настоящей работе), но с учетом 


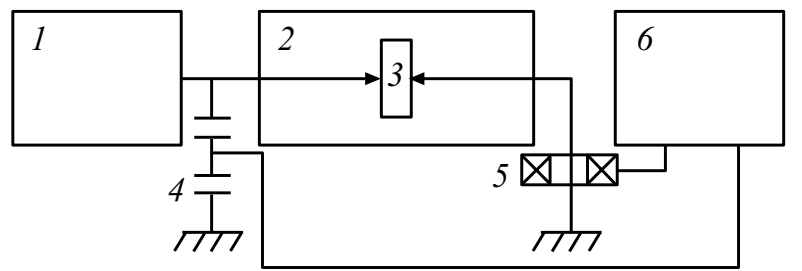

Рис. 2. Блок-схема экспериментальной установки: 1 - генератор коротких высоковольтных импульсов, $2-$ экспериментальная камера с электродами, 3 - образец, 4 - измеритель напряжения, 5 - измеритель тока, $6-$ осциллограф.

уменьшения их параметров на 20\% (при установке алюминиевой фольги) по соотношению (1), получим $p_{m}=450-600 \mathrm{MPa}$.

Для исследования стойкости образцов оксида алюминия с добавками графена к разрушению высоковольтным разрядом использован метод разрушения твердых диэлектриков в условиях приповерхностного пробоя нано- и субмикросекундной длительности [22], который основывается на открытии [23].

Общая блок-схема экспериментальной установки приведена на рис. 2 .

В качестве источника импульсов напряжения также использовался генератор коротких высоковольтных импульсов ГКВИ-300. Геометрия электродов и их материал описаны в работе [24].

С целью предотвращения пробоя по поверхности образца разрушение производилось в камере, заполненной дистиллированной водой. В каждом эксперименте с помощью емкостного делителя напряжения контролировался импульс напряжения, прикладываемый между электродами, а с помощью пояса Роговского измерялся ток, проходящий через образец. Сигналы с обоих устройств поступали на цифровой двухканальный осциллограф Tektronix TDS 2012.

Суть электроимпульсного разрушения образцов (дисков) заключается в образовании проводящих (плазменных) каналов в материале, их расширении после перекрытия ими межэлектродного промежутка, генерацию волн напряжения и хрупкое разрушение (раскалывание) материала диска [25]. При одноимпульсном нагружении выше порога разрушения образец раскалывается на два и более фрагментов. Чем ближе к порогу разрушения, тем меньше фрагментов и на пороге разрушения количество фрагментов становится равным 2 .

Механическая энергия $m$, которая непосредственно идет на разрушение образца, является частью полной электрической энергии $E_{e l}$, запасенной в источнике напряжения (ГКВИ-300), и определяется соотношением [26]:

$$
E_{m}=k_{e m} E_{e l},
$$

где $k_{e m}=0.06-0.08-$ коэффициент преобразования электрической энергии в механическую. Электрическая энергия определяется по регистрируемым осциллограммам тока и напряжения.

\section{1. Выбор критерия динамической прочности}

В работе [27] было установлено, что облучение одиночным импульсом вызывает разрушение твердого тела, если средняя плотность энергии, поглощенной за время импульса, превосходит характерный для этого вещества порог $W_{d}$. Например, тонкие пластинки кристаллов испытывали хрупкое разрушение, раскалываясь на части, при этом число осколков было велико и зависело от плотности пучка $\Phi$.

В $[28,29]$ предполагается, что динамическое разрушение твердого тела на фрагменты происходит при достижении критического напряжения $\sigma_{c r}$. В линейной механике разрушения предполагается, что непосредственным источником разрушения является упругая энергия твердого тела. Существует и другой подход, в основе которого лежит концепция кинетической энергии, связанной с центрами масс образующихся фрагментов.

В [30] на основе анализа работы [28] для каждого из подхода получены выражения для определения характерного размера образующихся фрагментов $a_{e}$ и $a_{k}$ :

$$
\begin{gathered}
a_{e} \approx 3\left(\frac{K_{I C}}{\sigma_{c r}}\right)^{2}, \\
a_{k} \approx 1.71\left(\frac{K_{I C}}{\rho c \dot{\varepsilon}}\right)^{2 / 3},
\end{gathered}
$$

где $K_{I C}-$ коэффициент трещиностойкости (критический коэффициент интенсивности напряжений), $\rho$ плотность разрушаемого материала, $c$ - скорость звука, $\dot{\varepsilon}$ - скорость деформации.

Из (3а) найдем количество фрагментов, на который может разрушиться наш диск (для (3б) суть зависимости будет такой же)

$$
N_{e} \approx \frac{d^{2}}{4 \beta} \cdot \frac{1}{3}\left(\frac{\sigma_{c r}}{K_{I C}}\right)^{4},
$$

где $\beta$ - коэффициент согласования из соотношения для равенства площадей $\left(\pi d^{2}\right)=N_{e} \beta_{e}^{2}$, здесь $d$ - диаметр образца.

Из полученного соотношения (4) следует, что количество фрагментов тем больше, чем меньше коэффициент трещиностойкости $K_{I C}$ (который в нашем случае следует понимать в динамическом смысле).

Поэтому условным критерием динамической прочности образцов, который указывал на влияние добавок графена, было количество фрагментов, на которые был разрушен образец. Аналогичный критерий принимался и в работе [31].

\section{2. Результаты экспериментов и их обсуждение}

\section{1. Фрактографический анализ исходного нанокомпозита}

С целью определения равномерности распределения графена был проведен фрактографический анализ исходных нанокомпозитов. На рис. 3 представлены картины 
$a$
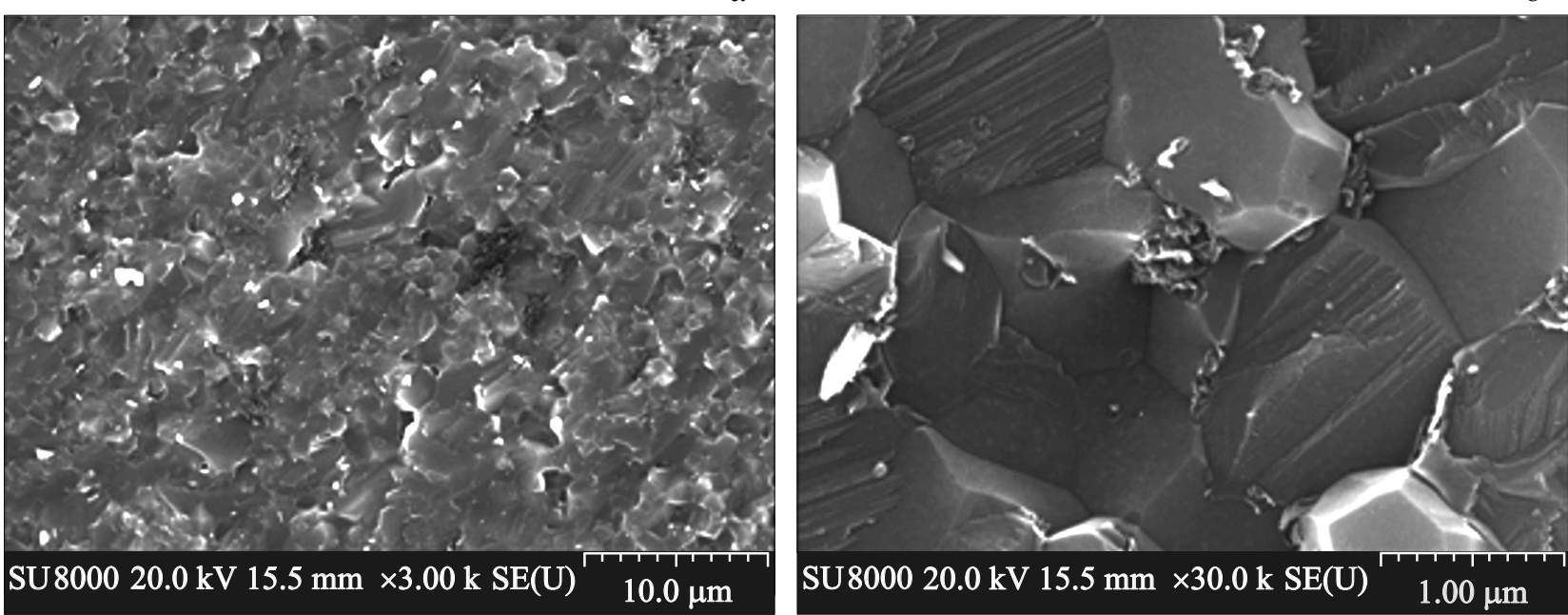

Pис. 3. Фрактографические картины излома нанокомпозита с $2 \%$ графена при увеличении: $a-\times 3000, b-\times 30000$.

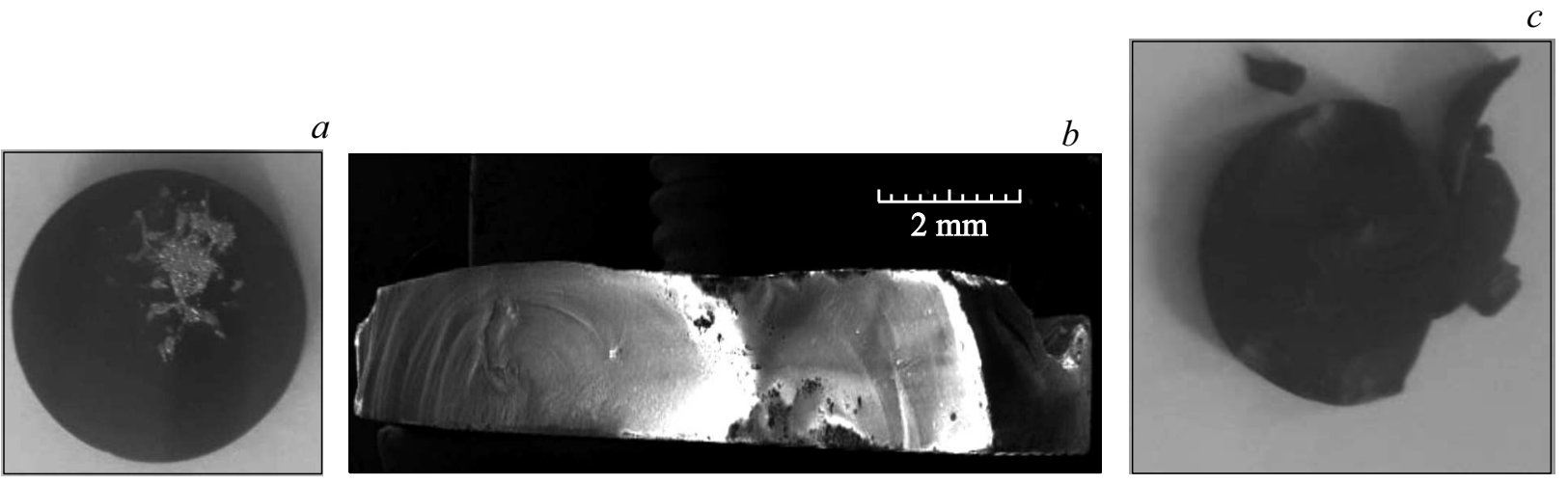

Рис. 4. Вид образцов после воздействия СЭП: $a-$ добавка графена отсутствует, $b-0.5$ mass.\% графена, $c-1.0$ mass.\% графена.

изломов в образце с $2 \%$ графена в различных точках и при разных увеличениях. Они позволяют качественно оценить равномерность распределения графена только в агломератах на микроуровне, поскольку наблюдение отдельных наночешуек требует высокого разрешения и большего увеличения. Тем не менее можно утверждать, что агломерированный графен составляет не более $5 \%$ площади рисунка (рис. $3, a$ ).

\section{2. Воздействие СЭП}

Воздействие СЭП на образцы оксида алюминия без добавок графена с установкой как титановой фольги, так и алюминиевой не приводило к разрушению образцов, при этом на лицевой поверхности образцов наблюдались вкрапления титановой или алюминиевой фольги (рис. $4, a)$. Расположение вкраплений находилось по большей части на периферии образца, что указывало на стохастичность процесса генерации пучка с катода.

При воздействии СЭП на образцы с добавками 0.5\% графена происходило разрушение образца на две неравные части, протяженность поверхности излома составляла $\sim 10 \mathrm{~mm}$ (рис. $4, b)$. Увеличение массовой доли графена до 1\% приводило к образованию множественного излома с несколькими отколовшимися частицами (рис. $4, c)$.

Наблюдением в лучах вторичных электронов установлено (рис. 5), что в образцах с добавками графена присутствуют дефекты. На изломе образца с $0.5 \%$ графена присутствуют частицы графена и поры (рис. 5,a), очевидно повлиявшие на прочность среды. Этот факт в некоторой степени указывает на то, что требуется усовершенствование технологии изготовления образцов.

Линии фронтов повреждения и рубцы на поверхности изломов показали (рис. $5, b$ ), что разрушение образцов (0.5 mass.\% графена) вызвано распространением деформации термомеханической природы, инициированной электронным лучом. Таким образом, роль теплового фактора в разрушение образца достаточно весома.

В целом же можно констатировать, что с увеличением процентного содержания графена в образцах оксида алюминия их хрупкость растет, однако эта хрупкость может быть связана в том числе с неоднородным распределением графена образцах, что может указывать на недоработки технологии изготовления образцов. 

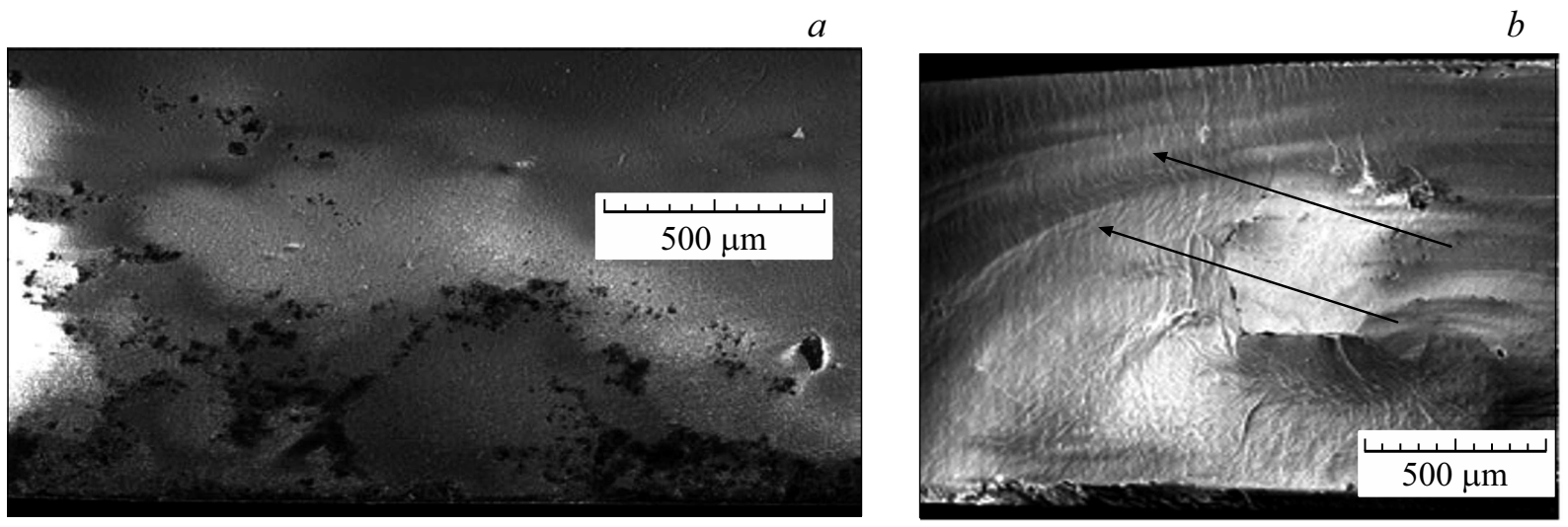

Рис. 5. Поверхности разрушения в образцах после воздействия СЭП: $a-$ излом образца с 0.5 mass.\% графена, $b-$ рубцы на поверхности излома (указаны стрелками).

$a$

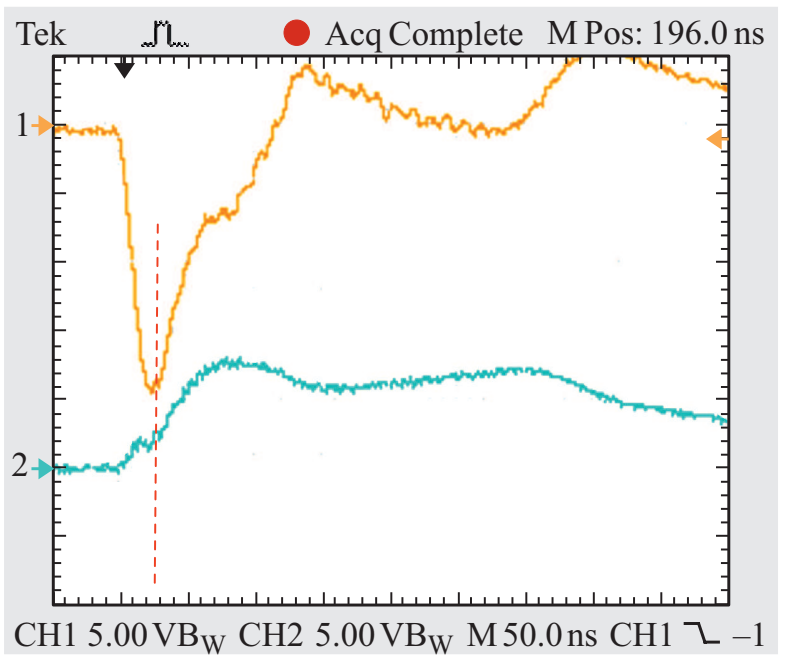

$b$

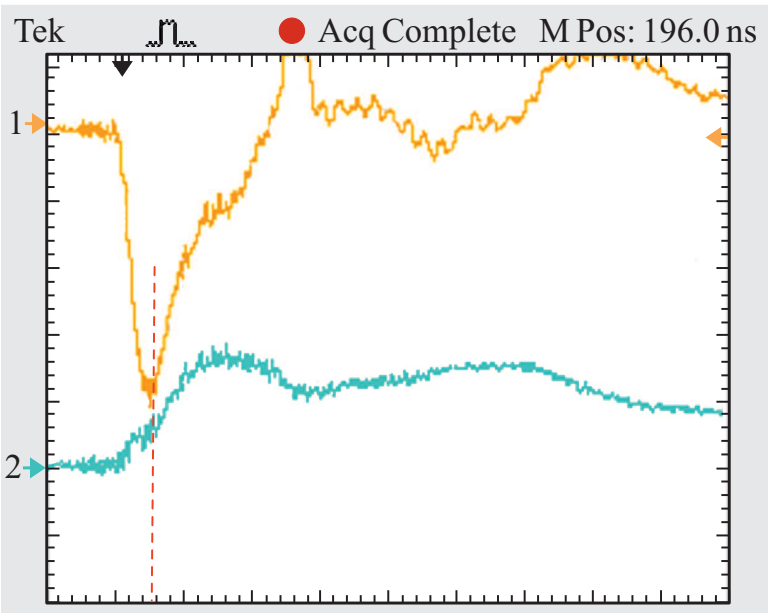

$\mathrm{CH} 15.00 \mathrm{VB}_{\mathrm{W}} \mathrm{CH} 25.00 \mathrm{VB}_{\mathrm{W}} \mathrm{M} 50.0 \mathrm{~ns} \mathrm{CH} 1 \mathrm{~L}-1$

Рис. 6. Типичные осциллограммы импульсов напряжения (1) и тока (2): $a-\mathrm{Al}_{2} \mathrm{O}_{3}+0.5$ mass.\% графена; $b-\mathrm{Al}_{2} \mathrm{O}_{3}+2.0$ mass. $\%$ графена (штриховой линией отмечен момент электрического пробоя).

\section{3. Воздействие высоковольтного разряда}

Как показали эксперименты, напряжение пробоя и ток, при котором он произошел, оказались практически одинаковыми во всех экспериментах, независимо от содержания графена (рис. 6). Поскольку толщина образцов достаточно мала, их фрагментация произошла далеко за порогом разрушения.

Количество фрагментов, на которые были разрушены образцы, в зависимости от содержания графена значительно варьировалось: при содержании графена 0.5количество фрагментов составляло 7-9; при $1.5 \%-11-14$; при 2\% - 17-20 (рис. 7). Учитывались только те фрагменты, характерный размер которых был не менее $0.5 \mathrm{~mm}$. В этом случае определялся дефицит массы образцов после их разрушения. Во всех случаях дефицит массы составлял не более $1.5 \%$.

Таким образом, с увеличением содержания графена число фрагментов, на которые распадаются образцы
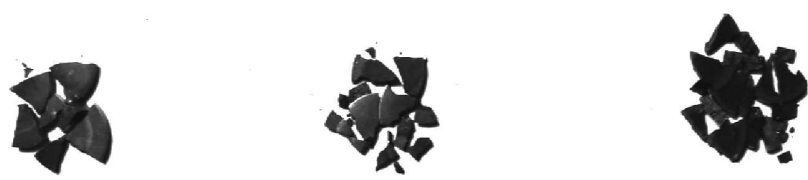

Рис. 7. Фрагменты разрушенных образцов: слева направо $0.5,1.5,2.0$ mass. \% графена.

при воздействии импульса высокого напряжения, резко возрастает. Полученный результат согласуется с данными [32], в которых добавление наноразмерных частиц оксида меди к исследуемым материалам приводило к общему охрупчиванию образцов при воздействии продуктов электрического взрыва проводника, находившегося в образце. Таким образом, в проведенном исследовании наноразмерные добавки (графен и нанопоры) не обладают упрочняющими свойствами, как этого следовало ожидать из анализа, проведенного в [33], хотя в нашем 
случае это может быть связано и с некоторым несовершенством технологии.

\section{Заключение}

Результаты исследования показали, что при воздействии СЭП и высоковольтного разряда увеличение содержания графена в пределах 0.5-2.0 mass.\% способствует увеличению количества фрагментов при разрушении. Подобный факт характерен для керамики, испытывающей хрупкое разрушение.

Сравнение свойств в таблице с результатами фрагментации при разрушении также подтверждает этот вывод. Так, введение графена в нанокомпозит резко увеличивает микротвердость, что обычно также указывает и на охрупчивание материала. В нанокомпозите это связано с ингибированием образования основной транскристаллической трещины и ее заменой межзеренным разрушением.

\section{Конфликт интересов}

Авторы заявляют, что у них нет конфликта интересов.

\section{Список литературы}

[1] Ю.А. Котов, В.В. Иванов. Вестник РАН, 78 (9), 777 (2008).

[2] А.В. Номоев. Письма в ЖТФ, 36 (21), 46 (2010).

[3] А.М. Брагов, В.Н. Чувильдеев, В.Н. Мелехин, М.С. Болдин, В.В. Баландин, А.В. Нохрин, А.А. Попов. ПМТФ, 61 (3), 207 (2020). DOI: 10.15372/PMTF20200322

[4] С.В. Матренин, Б.Б. Овечкин. Наноструктурные материалы в машиностроении (Изд-во ТПУ, Томск, 2009)

[5] K.S. Novoselov, A.K. Geim. Nature, 438, 197 (2005). DOI: 10.1038 /nature 04233

[6] H. Xia, X. Zhang, Z. Shi, H. Zhang, C. Zhao. Mater. Sci. Eng. (A), 639, 29 (2015). https://doi.org/10.1016/j.msea.2015.04.091

[7] H.J. Kim, S.M. Lee, Y.S. Oh, Y.H. Yang, Y.S. Lim, D.H. Yoon, C. Lee, J.Y. Kim, R.S. Ruoff. Scientific Reports, 4, 5176 (2014). DOI: $10.1038 /$ srep05176

[8] A. Centeno, V.G. Rocha, B. Alonso, A. Fernández, C.F. Gutierrez-Gonzalez, R. Torrecillas, A. Zurutuza. J. Europ. Ceram. Society, 33, 201 (2013). http://dx.doi.org/10.1016/j.jeurceramsoc.2013.07.007

[9] A. Borrell, R. Torrecillas, V.G. Rocha, A. Fernández. Wear, 274, 94 (2012). DOI: 10.1016/j.wear.2011.08.013

[10] S. Stankovich, D.A. Dikin, G.H. Dommett, K.M. Kohlhaas, E.J. Zimney, E.A. Stach, R.D. Piner, S.T. Nguyen, R.S. Ruoff. Nature, 442, 282 (2006). DOI: 10.1038 / nature04969

[11] Y.B. Adebayo, G.I. Douglas. J. Mater. Sci., 36 (20), 4995 (2001). DOI: 10.1023 / A: 1011885631876

[12] R. Azarafza, A. Arab, A. Mehidpoor. Intern. J. Adv. Design. Manufacturing Technol., 5 (5), 83 (2012).

[13] А.Г. Жолнин, И.В. Ковалева, М.С. Юрлова, А.М. Ильина, Е.Г. Григорьев, Е.А. Олевский. Физика и химия обработки материалов, 2, 73 (2015).
[14] E.A. Klyatskina, A. Borrell, E.G. Grigoriev, A.G. Zholnin, M.D. Salvador, V.V. Stolyarov. J. Ceram. Sci. Technol., 9 (39), 215 (2018). DOI: 10.4416/JCST2018-00006

[15] Ю.И. Мещеряков, В.А. Морозов. ЖТФ, 49 (9). С. 1982 (1979).

[16] Г.А. Месяц. Эктоны в вакуумном разряде: пробой, искра, дуга (Наука, М., 2000).

[17] Г.Г. Савенков, В.А. Морозов, М.А. Илюшин, В.М. Кац. Письма в ЖТФ, 44 (12), 39 (2018).

DOI: 10.21883/JTF.2021.03.50527.247-20 [G.G. Savenkov, V.A. Morozov, M.A. Ilyushin, V.M. Kats. Tech. Phys. Lett., 44 (12), 522 (2018). DOI: 10.1134/S1063785018060275]

[18] В.А. Морозов, Г.Г. Савенков, В.А. Брагин, В.М. Кац, A.A. Лукин. ЖТФ, 82 (5), 129 (2012). [V.A. Morozov, G.G. Savenkov, V.A. Bragin, V.M. Kats, A.A. Lukin. Tech. Phys., 57 (5), 129 (2012).]

[19] В.Н. Беломестных, Е.П. Теслева. Известия Томского политех. ун-та, 306 (5), 8 (2003).

[20] Д.С. Сандитов, В.Н. Беломестных. ЖТФ, 81 (11), 77 (2011).

[21] А.Ф. Федотов. Известия вузов. Порошковая металлургия и функциональные покрытия, 1, 32 (2015). https://doi.org/10.17073/1997-308X-2015-1-32-37

[22] А.Ф. Усов. Вестник Кольского НЦ РАН, 4, 166 (2012).

[23] А.А. Воробьев, Г.А. Воробьев, А.Т. Чепиков. Свидетельство на открытие № А-122 от 29.04.1998 с приоритетом от 14.12.1961.

[24] Г.Г. Зегря, Г.Г. Савенков, В.А. Морозов, А.Г. Зегря, Н.В. Улин, В.П. Улин, А.А. Лукин, В.А. Брагин, И.А. Оськин, Ю.М. Михайлов. ФТП, 51 (4), 501 (2017).

DOI: $10.21883 /$ JTF.2021.03.50527.247-20

[G.G. Zegrya, G.G. Savenkov, V.A. Morozov, A.G. Zegrya, N.V. Ulin, V.P. Ulin, A.A. Lukin, V.A. Bragin, I.A. Oskin, Y.M. Mikhailov. Semiconductors, 51 (4), 477 (2017). DOI: $10.1134 / \mathrm{S} 106478261704025 \mathrm{X}]$

[25] В.В. Лопатин, М.Д. Носков, Г.3. Усманов, А.А. Чеглоков. Физическая мезомеханика, 13 (6), 89 (2010).

[26] А.А. Лукин, В.А. Морозов, Ю.В. Судьенков. Вестник СПбГУ. Сер. 1, 2, 133 (2008).

[27] Д.И. Вайсбурд, И.Н. Балычев. Письма в ЖЭТФ, 15 (9), 527, (1979).

[28] D.E. Grady, M.M. Higtower. Shock-Wave and High-StrainRate Phenomena in materials (a.o.: M. Dekker, NY., 1992), p. 713.

[29] L.A. Glenn, A. Chudnovsky. J. Appl. Phys., 59 (4), 1379, (1986).

[30] А.Г. Иванов, В.А. Раевский, О.С. Воронцова. Физика горения и взрыв. 31 (2), 96 (1995).

[31] M. Michálek, M. Michálková, G. Blugan, J. Kuebler. Ceram. Intern., 44 (3), 3255 (2017). https://doi.org/10.1016/j.ceramint.2017.11.098

[32] Г.Г. Савенков, В.А. Морозов, А.А. Лукин. Письма в ЖТФ, 42 (22), 23 (2016). DOI: 10.21883/JTF.2021.03.50527.247-20 [G.G. Savenkov, V.A. Morozov, A.A. Lukin. Tech. Phys. Lett., 42 (11), 1110 (2016). DOI: 10.1134/S1063785016110201]

[33] В.Е. Панин, Е.Е. Дерюгин, С.Н. Кульков. ПМТФ, 51 (4), 127 (2010). 